\title{
A multiple objective approach for joint ordering and pricing planning problem with stochastic lead times
}

\author{
Zeinab Hosseini', Reza Ghasemy Yaghin ${ }^{2}$ and Maryam Esmaeili ${ }^{*}$
}

\begin{abstract}
The integration of marketing and demand with logistics and inventories (supply side of companies) may cause multiple improvements; it can revolutionize the management of the revenue of rental companies, hotels, and airlines. In this paper, we develop a multi-objective pricing-inventory model for a retailer. Maximizing the retailer's profit and the service level are the objectives, and shortage is allowed. We present the model under stochastic lead time with uniform and exponential distributions. Since pricing is important and influences demand, the demand is considered as a general function of price. The multiple-objective optimization model is solved using the weighting method as well as the L-P metric method. Concerning the properties of a nonlinear model, a genetic algorithm is taken into account to find the optimal solutions for the selling price, lot size, and reorder point. Finally, numerical examples with sensitivity analysis regarding key parameters are provided.
\end{abstract}

Keywords: Multi-objective nonlinear optimization; Pricing; Stochastic lead time; L-P metric method; Genetic algorithm

\section{Introduction}

Planning and inventory control is one of the major issues in industrial engineering; it is also one of the inevitable activities in each organization. Therefore, there exist several studies in this research area. Here, we investigate two general groups of papers. The first group considers inventory models with pricing. The integration of inventory and pricing policies leads to the joint optimization of the whole system and maximization of the total profit. Selling price consumer selection can gravitate to the customers. Lee (2011) considered two pricing policies based on two service levels. The author concluded that increasing the price leads some customers towards low service levels with lower prices. Whitin (1955) was the first researcher to formulate a newsboy model with price effect. In that model, the probability distribution of demand depended on the unit selling price where price was a decision variable. Abad (2003, 2008), Dye (2007), and Dye and Hsieh (2010)

\footnotetext{
* Correspondence: esmaeili_m@alzahra.ac.ir

${ }^{1}$ Department of Industrial Engineering, Alzahra University, Tehran, Iran Full list of author information is available at the end of the article
}

assumed deteriorating items and allowable shortage. They presented models that considered the price as a decision variable. Abad (2003, 2008) and Dye (2007) considered demand as a general function of price. Mukhopadhyay et al. (2004) and Esmaeili (2009) studied infinite planning horizon where shortage was not allowed. Mukhopadhyay considered demand to be a nonlinear function of price, while in the model of Esmaeili, demand was a general function. The annual profit of the manufacturer is maximized to determine the selling price, marketing expenditure, and lot size. Sana (2011) presented a stochastic inventory in which demand was considered to be dependent on the random selling price. Dye and Hsieh (2013) studied an advanced sales system with deteriorating items where prices were dependent on demand. They showed that advanced sales price is lower than the spot sales price. Sadjadi et al. (2012) used geometric programming (GP) to obtain optimal lot sizing, pricing, and marketing decisions such that the profit is maximized. However, using a single objective function is the major shortcoming of the models.

Most inventory models aggregate several cost concepts and service requirements into a single objective and use 
Table 1 Comparison between the most relevant models in literature

\begin{tabular}{|c|c|c|c|c|c|c|}
\hline Research papers & $\begin{array}{l}\text { Objective } \\
\text { function }\end{array}$ & Objective function & Pricing & Demand & Lead time & Solution method \\
\hline $\begin{array}{l}\text { Sheikh Sajadieh and } \\
\text { Akbari Jokar (2009) }\end{array}$ & Single & Cost minimization & $\begin{array}{l}\text { Not } \\
\text { considered }\end{array}$ & Constant & $\begin{array}{l}\text { Stochastic } \\
\text { (uniform) }\end{array}$ & Exact \\
\hline $\begin{array}{l}\text { Sheikh Sajadieh } \\
\text { et al. (2009) }\end{array}$ & Single & Cost minimization & $\begin{array}{l}\text { Not } \\
\text { considered }\end{array}$ & Constant & $\begin{array}{l}\text { Stochastic } \\
\text { (exponential) }\end{array}$ & Exact \\
\hline Esmaeili (2009) & Single & Profit maximization & Considered & $\begin{array}{l}\text { Price } \\
\text { dependent }\end{array}$ & Constant & Exact \\
\hline Tsou (2008) & Multiple & $\begin{array}{l}\text { Cost minimization, frequency of stock out } \\
\text { occasions, and number of items stocked out }\end{array}$ & $\begin{array}{l}\text { Not } \\
\text { considered }\end{array}$ & Stochastic & Constant & $\begin{array}{l}\text { TOPSIS and MOPSO } \\
\text { algorithm }\end{array}$ \\
\hline $\begin{array}{l}\text { Dye and Hsieh } \\
\text { (2013) }\end{array}$ & Single & Profit maximization & Considered & $\begin{array}{l}\text { Price } \\
\text { dependent }\end{array}$ & Constant & Exact \\
\hline Proposed model & Multiple & Profit maximization and service level & Considered & $\begin{array}{l}\text { Price } \\
\text { dependent }\end{array}$ & $\begin{array}{l}\text { Stochastic } \\
\text { (uniform and } \\
\text { exponential) }\end{array}$ & $\begin{array}{l}\text { L-P metric, } \\
\text { Weighting and GA } \\
\text { algorithm }\end{array}$ \\
\hline
\end{tabular}

traditional methods to solve them. Nonetheless, one of the significant characteristics of modern business is the multiple criteria context of retail industries.

In the second group, the decision maker seeks to maximize or minimize two or more objectives simultaneously. This group of models has been applied in several fields, but few of these multi-objective problems have dealt with inventory control optimization.

Padmanabhan and Vart (1990) solved a multi-objective inventory model with deteriorating items and stockdependent demand by a nonlinear goal programming method. Agrell (1995) proposed a multi-objective inventory model with three objective functions. These objectives included minimization of average total relevant annual cost, annual average frequency of stock out occasions, and annual average number of times stock out.

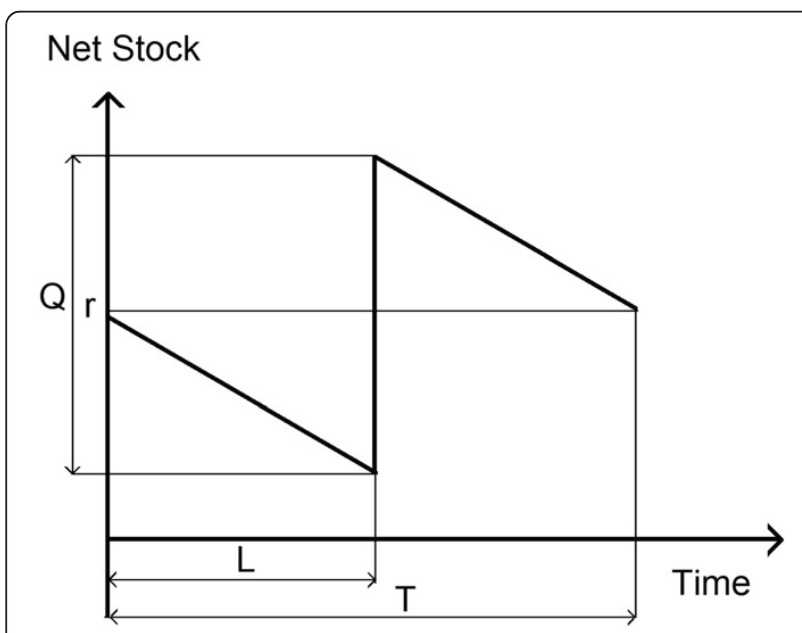

Figure 1 Case1 $r>b D$.
Considering lot size and safety factor as decision variables, it is assumed that planning horizon is infinite, demand has a normal distribution, and shortage is allowed. Later Tsou (2008, 2009) and Moslemi and Zandieh (2011) considered Agrell's model. However, nondominated solutions of a reorder point and order size have been obtained using multi-objective particle swarm optimization algorithm (MOPSO). Moreover, TOPSIS was used to rank the nondominated solutions using the preference of decision makers (Tsou 2008). Tsou (2009) involved MOPSO and multi-objective electromagnetismlike optimization (MOEMO) algorithms to obtain nondominated solutions of lot size and safety stock. Moslemi and Zandieh (2011) created some strategies based on the MOPSO algorithm in continuous review stochastic inventory control system.

Many researchers have considered deterioration in a multi-item multi-objective inventory model under a

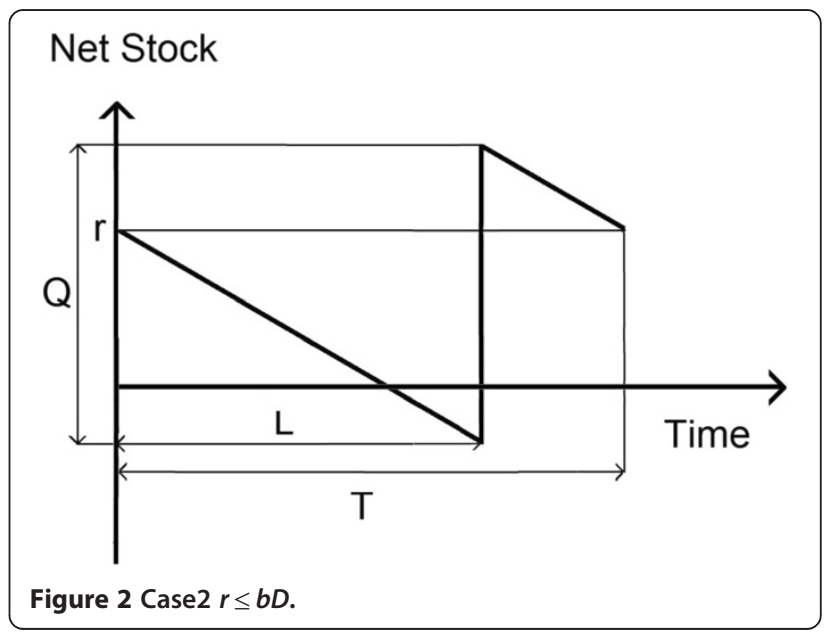



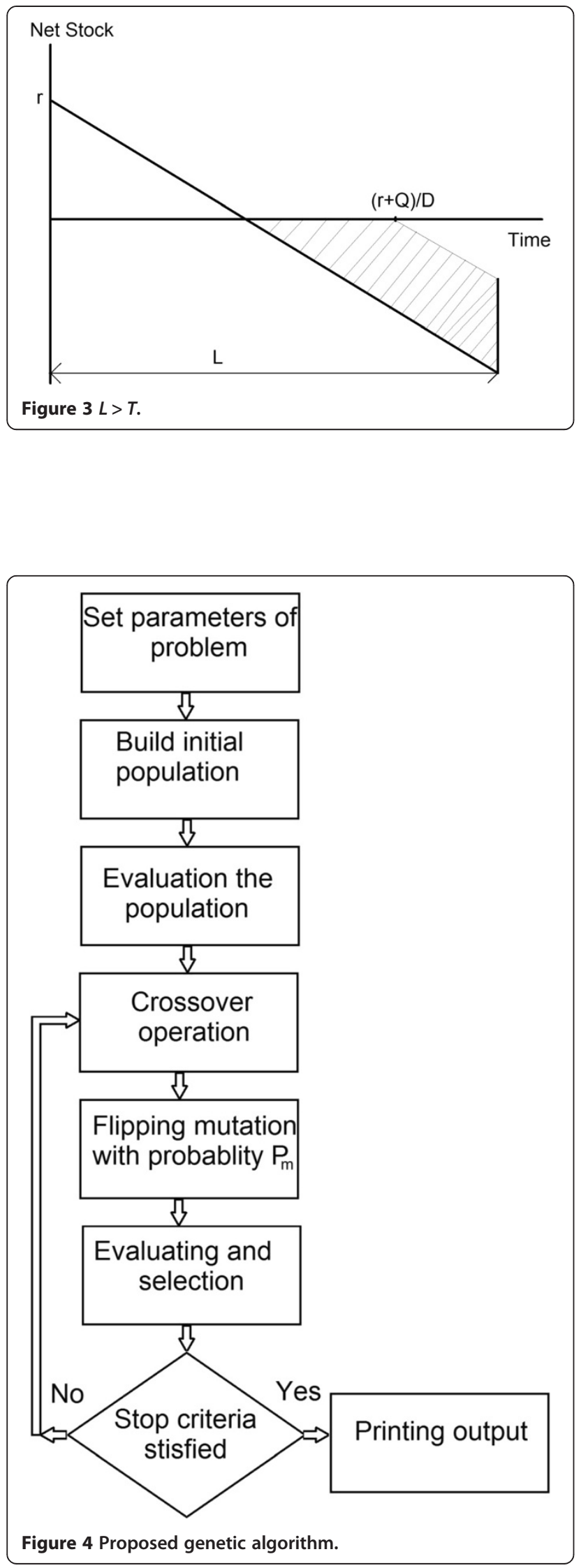

Table 2 Optimal results of model with uniform lead time

\begin{tabular}{lcccccc}
\hline Method & Weights of objectives & $\boldsymbol{P}^{*}$ & $\boldsymbol{Q}^{*}$ & $\boldsymbol{r}^{*}$ & $\boldsymbol{Z}^{*}$ & $\mathbf{S L}^{*}$ \\
\hline Weighting & & 89 & 107 & 32 & 64,444 & 0.4055 \\
L-P metric, $p=1$ & $\mathrm{~W} 1=0.2$ & 88 & 197 & 79 & 63,476 & 0.9987 \\
L-P metric, $p=2$ & $\mathrm{~W} 2=0.8$ & 88 & 181 & 79 & 63,508 & 0.9987 \\
Weighting & & 90 & 107 & 31 & 65,107 & 0.3938 \\
L-P metric, $p=1$ & $\mathrm{~W} 1=0.4$ & 90 & 198 & 78 & 64,808 & 0.9909 \\
L-P metric, $p=2$ & $\mathrm{~W} 2=0.6$ & 90 & 179 & 78 & 64,845 & 0.9909 \\
Weighting & & 90 & 108 & 29 & 65,108 & 0.3684 \\
L-P metric, $p=1$ & $W 1=0.6$ & 90 & 196 & 78 & 64,812 & 0.9909 \\
L-P metric, $p=2$ & $W 2=0.4$ & 90 & 176 & 78 & 64,850 & 0.9909 \\
\hline
\end{tabular}

fuzzy environment. For instance, Roy and Maiti (1998) maximized profit and minimized wastage cost; while the demand was dependent on the inventory level, planning horizon was finite and shortage was allowed. To obtain optimal solution, they used fuzzy nonlinear programming (FNLP) and fuzzy additive goal programming (FAGP) methods considering budget and space constraints. However, Mandal et al. (2005) included storage space, number of orders, and production cost in their model and achieved optimal solution by applying GP. In addition, Maity and Maiti (2008) and Islam (2008) presented a multi-item multi-objective inventory model under fuzzy inflation and discounting. Maity and Maiti (2008) assumed that time horizon is finite, shortage is allowed, and demand is dependent on advertisement. They have used utility function method (UFM) and generalized reduced gradient (GRG) methods to obtain optimal solution. Islam (2008) considered an infinite planning horizon under the limitation of space capacity and total shortage cost constraints with demand uniformly distributed and dependent on the marketing

Table 3 Optimal results of model with exponential lead time

\begin{tabular}{lcccccc}
\hline Method & Weights of objectives & $\boldsymbol{P}^{*}$ & $\mathbf{Q}^{*}$ & $\boldsymbol{r}^{*}$ & $\boldsymbol{Z}^{*}$ & $\mathbf{S L}^{*}$ \\
\hline Weighting & & 89 & 107 & 32 & 64,444 & 0.4055 \\
L-P metric, $p=1$ & $\mathrm{~W} 1=0.2$ & 88 & 197 & 79 & 63,476 & 0.9987 \\
L-P metric, $p=2$ & $\mathrm{~W} 2=0.8$ & 88 & 181 & 79 & 63,508 & 0.9987 \\
Weighting & & 90 & 107 & 31 & 65,107 & 0.3938 \\
L-P metric, $p=1$ & $\mathrm{~W} 1=0.4$ & 90 & 198 & 78 & 64,808 & 0.9909 \\
L-P metric, $p=2$ & $\mathrm{~W} 2=0.6$ & 90 & 179 & 78 & 64,845 & 0.9909 \\
Weighting & & 90 & 108 & 29 & 65,108 & 0.3684 \\
L-P metric, $p=1$ & $\mathrm{~W} 1=0.6$ & 90 & 196 & 78 & 64,812 & 0.9909 \\
L-P metric, $p=2$ & $\mathrm{~W} 2=0.4$ & 90 & 176 & 78 & 64,850 & 0.9909 \\
\hline
\end{tabular}


Table 4 Sensitivity analysis of the uniform model with respect to $C$ - weighting method

\begin{tabular}{lcccc}
\hline $\boldsymbol{c}=$ & $\mathbf{6}$ & $\mathbf{9}$ & $\mathbf{1 2}$ & $\mathbf{1 5}$ \\
\hline$P^{*}$ & 82 & 88 & 94 & 100 \\
$Q^{*}$ & 110 & 108 & 108 & 107 \\
$r^{*}$ & 30 & 30 & 29 & 28 \\
$Z^{*}$ & 63,038 & 64,602 & 66,095 & 67,515 \\
$\mathrm{SL}^{*}$ & 0.3738 & 0.3792 & 0.3720 & 0.3646 \\
\hline
\end{tabular}

Table 5 Sensitivity analysis of the uniform model with respect to $h$ - weighting method

\begin{tabular}{lcccc}
\hline $\boldsymbol{h}=$ & $\mathbf{2}$ & $\mathbf{4}$ & $\mathbf{6}$ & $\mathbf{8}$ \\
\hline$P^{*}$ & 84 & 88 & 92 & 95 \\
$Q^{*}$ & 160 & 120 & 101 & 92 \\
$r^{*}$ & 40 & 31 & 27 & 23 \\
$Z^{*}$ & 61,251 & 63,827 & 66,377 & 68,244 \\
$S L^{*}$ & 0.5008 & 0.3919 & 0.3447 & 0.2958 \\
\hline
\end{tabular}

Table 6 Sensitivity analysis of the uniform model with respect to $\pi$ - weighting method

\begin{tabular}{lcccc}
\hline $\boldsymbol{\pi}=$ & $\mathbf{1 5}$ & $\mathbf{2 5}$ & $\mathbf{3 5}$ & $\mathbf{4 5}$ \\
\hline$P^{*}$ & 60 & 80 & 100 & 120 \\
$Q^{*}$ & 121 & 112 & 106 & 100 \\
$r^{*}$ & 13 & 26 & 31 & 35 \\
$Z^{*}$ & 43,543 & 58,314 & 71,505 & 83,105 \\
$\mathrm{SL}^{*}$ & 0.1539 & 0.3224 & 0.4036 & 0.4797 \\
\hline
\end{tabular}

Table 7 Sensitivity analysis of the uniform model with to respect $\boldsymbol{a}$ - weighting method

\begin{tabular}{lcccc}
\hline $\boldsymbol{a}=$ & $\mathbf{0 . 5}$ & $\mathbf{1 . 5}$ & $\mathbf{2 . 5}$ & $\mathbf{3 . 5}$ \\
\hline$P^{*}$ & 90 & 90 & 90 & 90 \\
$Q^{*}$ & 118 & 111 & 105 & 98 \\
$r^{*}$ & 36 & 32 & 27 & 23 \\
$Z^{*}$ & 75,859 & 68,691 & 61,524 & 54,395 \\
$\mathrm{SL}^{*}$ & 0.3927 & 0.3854 & 0.3629 & 0.3498 \\
\hline
\end{tabular}

Table 8 Sensitivity analysis of the uniform model with respect to $C$ - L-P metric method $(p=2)$

\begin{tabular}{lcccc}
\hline $\boldsymbol{c}=$ & $\mathbf{6}$ & $\mathbf{9}$ & $\mathbf{1 2}$ & $\mathbf{1 5}$ \\
\hline$P^{*}$ & 82 & 87 & 94 & 100 \\
$Q^{*}$ & 178 & 178 & 172 & 167 \\
$r^{*}$ & 80 & 79 & 77 & 75 \\
$Z^{*}$ & 62,774 & 63,670 & 65,846 & 67,280 \\
$\mathrm{SL}^{*}$ & 0.9968 & 0.9963 & 0.9878 & 0.9766 \\
\hline
\end{tabular}

Table 9 Sensitivity analysis of the uniform model with respect to $h$ - L-P metric method $(p=2)$

\begin{tabular}{lcccc}
\hline $\boldsymbol{h}=$ & $\mathbf{2}$ & $\mathbf{4}$ & $\mathbf{6}$ & $\mathbf{8}$ \\
\hline$P^{*}$ & 83 & 88 & 92 & 95 \\
$Q^{*}$ & 178 & 176 & 172 & 169 \\
$r^{*}$ & 80 & 79 & 77 & 76 \\
$Z^{*}$ & 60,507 & 63,645 & 66,050 & 67,757 \\
$\mathrm{SL}^{*}$ & 0.9992 & 0.9987 & 0.9829 & 0.9774 \\
\hline
\end{tabular}

Table 10 Sensitivity analysis of the uniform model with respect to $\pi$ - L-P metric method $(p=2)$

\begin{tabular}{lcccc}
\hline $\boldsymbol{\pi}=$ & $\mathbf{1 5}$ & $\mathbf{2 5}$ & $\mathbf{3 5}$ & $\mathbf{4 5}$ \\
\hline$P^{*}$ & 60 & 80 & 100 & 120 \\
$Q^{*}$ & 192 & 188 & 169 & 161 \\
$r^{*}$ & 84 & 80 & 76 & 72 \\
$Z^{*}$ & 43,197 & 58,020 & 71,271 & 82,902 \\
$\mathrm{SL}^{*}$ & 0.9943 & 0.9921 & 0.9896 & 0.9868 \\
\hline
\end{tabular}

Table 11 Sensitivity analysis of the uniform model with respect to $a$ - L-P metric method $(p=2)$

\begin{tabular}{lcccc}
\hline $\boldsymbol{a}=$ & $\mathbf{0 . 5}$ & $\mathbf{1 . 5}$ & $\mathbf{2 . 5}$ & $\mathbf{3 . 5}$ \\
\hline$P^{*}$ & 90 & 90 & 90 & 90 \\
$Q^{*}$ & 203 & 183 & 163 & 143 \\
$r^{*}$ & 91 & 82 & 73 & 64 \\
$Z^{*}$ & 75,549 & 68,422 & 61,295 & 54,167 \\
$S L^{*}$ & 0.9926 & 0.9875 & 0.9812 & 0.9732 \\
\hline
\end{tabular}


Table 12 Sensitivity analysis of the uniform model with respect to $C$ - L-P metric method $(p=1)$

\begin{tabular}{lcccc}
\hline $\boldsymbol{c}=$ & $\mathbf{6}$ & $\mathbf{9}$ & $\mathbf{1 2}$ & $\mathbf{1 5}$ \\
\hline$P^{*}$ & 82 & 87 & 94 & 100 \\
$Q^{*}$ & 201 & 198 & 193 & 188 \\
$r^{*}$ & 80 & 79 & 77 & 75 \\
$Z^{*}$ & 62,730 & 63,632 & 65,806 & 67,241 \\
$\mathrm{SL}^{*}$ & 0.9968 & 0.9963 & 0.9878 & 0.9766 \\
\hline
\end{tabular}

cost. To minimize inventory, marketing, and production costs, the optimal solution was obtained using the GP method. A significant shortcoming of all these models is that they only regard a deterministic lead time. However, the lead time in the real world is usually a random variable. Moreover, the lead time has an effective role in determining the optimal policy of inventory models. Recently, Hosseini et al. (2012) presented a multi-objective model with uniformly distributed lead time to optimize retailing activities.

Price and service level are important factors in attracting customers and increasing their satisfaction (Liang et al. 2008). Therefore, in this paper, a multiobjective inventory model is presented which includes the retailer's profit and service level. With infinite planning horizon and allowable shortage, we assume that lead time has uniform and exponential distribution while demand is a general function of price. Selling price, lot size, and reorder point are obtained by maximizing both the retailer's profit and service level. Genetic algorithm (GA) is used since the model is complex and nonlinear. In the end, a numerical example is provided along with sensitivity analysis on key parameters including shortage, purchasing and holding costs, and demand elasticity. A comparison between the proposed model and the most relevant models in the literature has been provided in Table 1 .

This paper is organized as follows: In the 'Model formulation and assumption' section, notation, assumptions, and mathematical model are provided. Solution

Table 13 Sensitivity analysis of the uniform model with respect to $h$ - L-P metric method $(p=1)$

\begin{tabular}{lcccc}
\hline $\boldsymbol{h}=$ & $\mathbf{2}$ & $\mathbf{4}$ & $\mathbf{6}$ & $\mathbf{8}$ \\
\hline$P^{*}$ & 83 & 88 & 92 & 95 \\
$Q^{*}$ & 201 & 198 & 193 & 192 \\
$r^{*}$ & 80 & 79 & 77 & 76 \\
$Z^{*}$ & 60,497 & 63,614 & 66,000 & 67,680 \\
$\mathrm{SL}^{*}$ & 0.9992 & 0.9987 & 0.9829 & 0.9774 \\
\hline
\end{tabular}

Table 14 Sensitivity analysis of the uniform model with respect to $\pi$ - L-P metric method $(p=1)$

\begin{tabular}{lcccc}
\hline $\boldsymbol{\pi}=$ & $\mathbf{1 5}$ & $\mathbf{2 5}$ & $\mathbf{3 5}$ & $\mathbf{4 5}$ \\
\hline$P^{*}$ & 60 & 80 & 100 & 120 \\
$Q^{*}$ & 256 & 201 & 192 & 178 \\
$r^{*}$ & 84 & 80 & 76 & 71 \\
$Z^{*}$ & 43,065 & 57,955 & 71,228 & 82,876 \\
$\mathrm{SL}^{*}$ & 0.9943 & 0.9921 & 0.9869 & 0.9731 \\
\hline
\end{tabular}

algorithm is presented in the 'Solution procedure' section. The 'Numerical example and sensitivity analysis' section includes the numerical example and sensitivity analysis on the key parameters of the model. Finally, the suggestions and results obtained from this study are presented in the 'Conclusions' section.

\section{Model formulation and assumptions}

This section introduces the notations, assumptions, decision variables, and input parameters of our model.

\section{Notation}

The following is the notation:

- $P$ selling price (decision variable)

- $Q$ lot size (decision variable)

- $r$ reorder point (decision variable)

- $C$ purchase cost (US\$ per unit)

- $A$ ordering cost (US\$ per order)

- $h$ holding cost (US\$ per unit)

- $\pi$ shortage cost (US\$ per unit)

- $L$ lead time

- $T$ duration of inventory cycle

- $D(P)$ demand rate; for simplicity, we let $D \equiv D(P)$

- Sr sales revenue

- TC expected total cost

- $Z$ retailer's profit

- SL service level

\section{Assumptions}

The proposed models are based on the following assumptions:

1- Planning horizon is infinite.

2- Shortage is allowed and completely back-ordered.

3 - Similar to the models proposed by Abad (2003, 2008), Dye (2007), and Esmaeili (2009), demand is represented by a general function of price.

4- The lead time is stochastic and follows uniform and exponential distribution.

5- Inventory is continuously reviewed. 

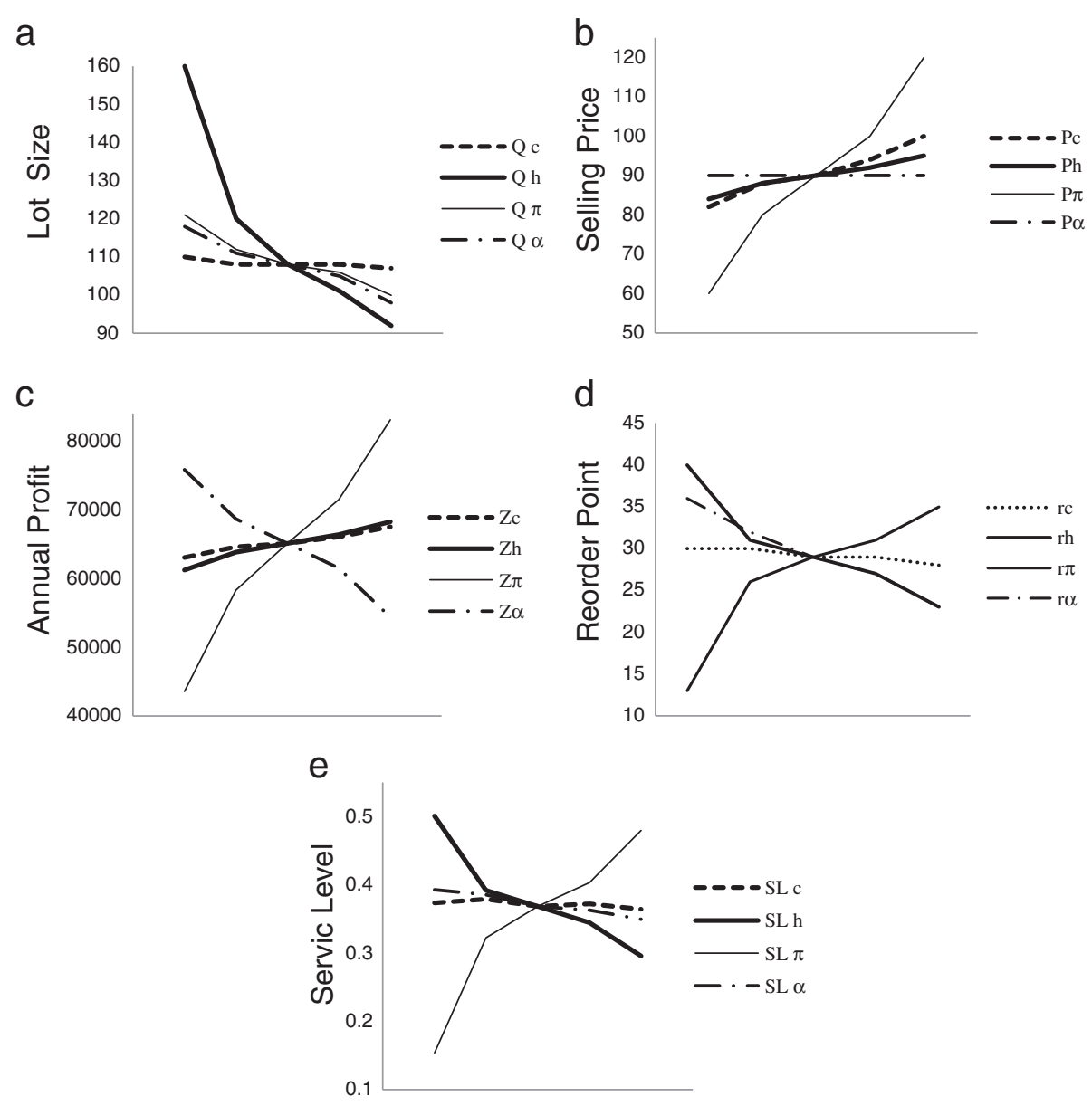

Figure 5 Effect of key parameters on (a) Q, (b) P, (c) Z, (d) r, and (e) SL (uniform model, weighting method).

6- The customers are myopic and thus make a purchase immediately if the price is below their willingness to pay without considering future prices.

\section{Mathematical model}

In this section, the multi-objective inventory model, including the retailer's profit and service level with uniform and exponential lead time, is presented.

\section{Modeling with uniform distribution}

Consider a retailer who is going to maximize the profit and attract the customers to increase their satisfaction. Therefore, the model would be a multi-objective inventory model with two objectives. By maximizing the service level and the retailer's profit, the optimal selling price, lot size, and reorder point $(P, Q$, and $r$ ) are to be obtained. The costs include purchasing, ordering, holding, and shortage. The lead time is stochastic and follows a uniform distribution with parameters $a$ and $b(L \sim U[\mathrm{a}, \mathrm{b}])$. Therefore, its probability density is as follows:

$$
f_{l}(L)=\frac{1}{b-a} \quad a \leq 1 \leq b .
$$

Since the lead time is assumed to be a random variable, two cases can occur during each cycle time (Sheikh Sajadieh and Akbari Jokar 2009; Taleizadeh et al. 2010). In the first case, the reorder point is greater than the maximum demand during lead time. Therefore, the retailer does not face any shortage (Figure 1). In the second case, the ordering point is smaller than or equal to the maximum demand during lead time; it is probable to face shortage (Figure 2).

The annual profit function of the model is expressed as the retailer's profit $=$ sales revenue - purchase cost ordering cost-holding cost-shortage cost, which respectively are as follows:

$$
S_{r}=P D
$$



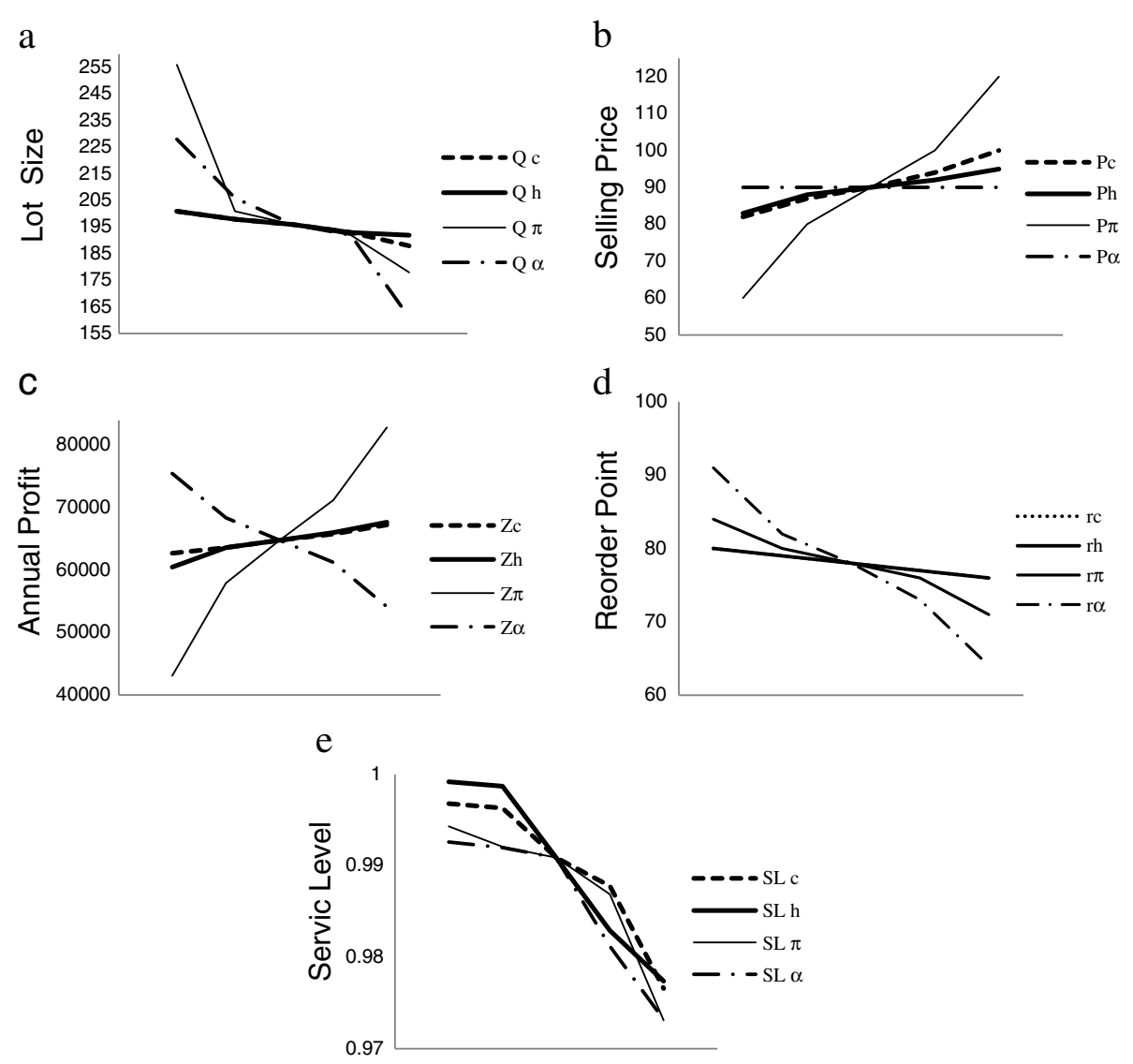

Figure 6 Effect of key parameters on (a) Q, (b) P, (c) Z, (d) r, and (e) SL (uniform model, L-P metric method $p=1$ ).

$\mathrm{TC}(P, Q, r)$

$$
\begin{aligned}
= & C D+\frac{D A}{Q}+\frac{D h}{Q} \int_{a}^{r / D}\left(r l-\frac{D l^{2}}{2}\right) f_{l}(L) d l \\
& +\frac{r h}{Q} \int_{a}^{b}(Q-D) f_{l}(L) d l+\frac{h}{2 Q} \int_{a}^{b}(Q-D l)^{2} f_{l}(L) d l \\
& +\frac{r^{2} h}{2 Q} \int_{r / D}^{b} f_{l}(L) d l+\frac{\pi}{2 Q} \int_{r / D}^{b}(D l-r)^{2} f_{l}(L) d l
\end{aligned}
$$

By substituting Equation 1 in Equation 3, we have

$$
\begin{aligned}
Z(P, Q, r)= & P D-C D-\frac{D A}{Q}-h r \\
& -\frac{h\left(2 r^{2}-3 r D^{2} a^{2}+D^{3} a^{3}\right)}{6 D Q(b-a)}+\frac{h r D(a+b)}{2 Q} \\
& -\frac{h(Q-D b-D a)}{2}-\frac{h D^{2}\left(a^{2}+a b+b^{2}\right)}{6 Q} \\
& -\frac{h r^{2}(D b-r)}{2 D Q(b-a)}-\frac{\pi(D b-r)^{3}}{6 D Q(b-a)}
\end{aligned}
$$

Table 15 Sensitivity analysis of the uniform model with respect to $a$ - L-P metric method $(p=1)$

\begin{tabular}{lcccc}
\hline $\boldsymbol{a}=$ & $\mathbf{0 . 5}$ & $\mathbf{1 . 5}$ & $\mathbf{2 . 5}$ & $\mathbf{3 . 5}$ \\
\hline$P^{*}$ & 90 & 90 & 90 & 90 \\
$Q^{*}$ & 228 & 206 & 192 & 161 \\
$r^{*}$ & 91 & 82 & 73 & 64 \\
$Z^{*}$ & 75,499 & 68,378 & 61,240 & 54,136 \\
$\mathrm{SL}^{*}$ & 0.9926 & 0.9875 & 0.9812 & 0.9732 \\
\hline
\end{tabular}

Table 16 Sensitivity analysis of the exponential model with respect to $C$ - the weighting method

\begin{tabular}{lcccc}
\hline $\boldsymbol{c}=$ & $\mathbf{6}$ & $\mathbf{9}$ & $\mathbf{1 2}$ & $\mathbf{1 5}$ \\
\hline$P^{*}$ & 82 & 88 & 94 & 100 \\
$Q^{*}$ & 127 & 127 & 127 & 127 \\
$r^{*}$ & 32 & 30 & 28 & 27 \\
$Z^{*}$ & 62,903 & 64,470 & 65,965 & 67,388 \\
$\mathrm{SL}^{*}$ & 0.5495 & 0.5316 & 0.5129 & 0.5049 \\
\hline
\end{tabular}


Table 17 Sensitivity analysis of the exponential model with respect to $h$ - the weighting method

\begin{tabular}{lcccc}
\hline $\boldsymbol{h}=$ & $\mathbf{2}$ & $\mathbf{4}$ & $\mathbf{6}$ & $\mathbf{8}$ \\
\hline$P^{*}$ & 84 & 88 & 92 & 95 \\
$Q^{*}$ & 187 & 143 & 122 & 110 \\
$r^{*}$ & 49 & 33 & 24 & 18 \\
$Z^{*}$ & 61,172 & 63,711 & 66,235 & 68,084 \\
$\mathrm{SL}^{*}$ & 0.7068 & 0.5658 & 0.4581 & 0.3705 \\
\hline
\end{tabular}

Table 18 Sensitivity analysis of the exponential model with respect to $\pi$ - weighting method

\begin{tabular}{lcccc}
\hline $\boldsymbol{\pi}=$ & $\mathbf{1 5}$ & $\mathbf{2 5}$ & $\mathbf{3 5}$ & $\mathbf{4 5}$ \\
\hline$P^{*}$ & 60 & 80 & 100 & 120 \\
$Q^{*}$ & 129 & 127 & 127 & 125 \\
$r^{*}$ & 13 & 24 & 33 & 38 \\
$Z^{*}$ & 4,345 & 5,819 & 7,136 & 8,294 \\
$\mathrm{SL}^{*}$ & 0.2649 & 0.4485 & 0.5765 & 0.6471 \\
\hline
\end{tabular}

Table 19 Sensitivity analysis of the exponential model with respect to $a$ - weighting method

\begin{tabular}{lcccc}
\hline $\boldsymbol{a}=$ & $\mathbf{0 . 5}$ & $\mathbf{1 . 5}$ & $\mathbf{2 . 5}$ & $\mathbf{3 . 5}$ \\
\hline$P^{*}$ & 90 & 90 & 90 & 90 \\
$Q^{*}$ & 144 & 136 & 126 & 118 \\
$r^{*}$ & 35 & 30 & 26 & 21 \\
$Z^{*}$ & 75,701 & 68,551 & 61,403 & 54,255 \\
$\mathrm{SL}^{*}$ & 0.5339 & 0.5144 & 0.5028 & 0.4720 \\
\hline
\end{tabular}

Table 20 Sensitivity analysis of the exponential model with respect to $C$ - L-P metric method $(p=2)$

\begin{tabular}{lcccc}
\hline $\boldsymbol{c}=$ & $\mathbf{6}$ & $\mathbf{9}$ & $\mathbf{1 2}$ & $\mathbf{1 5}$ \\
\hline$P^{*}$ & 82 & 88 & 94 & 100 \\
$Q^{*}$ & 421 & 411 & 398 & 383 \\
$r^{*}$ & 168 & 164 & 159 & 153 \\
$Z^{*}$ & 61,792 & 63,394 & 64,936 & 66,415 \\
$\mathrm{SL}^{*}$ & 0.9848 & 0.9842 & 0.9831 & 0.9814 \\
\hline
\end{tabular}

Table 21 Sensitivity analysis of the exponential model with respect to $h$ - L-P metric method $(p=2)$

\begin{tabular}{lcccc}
\hline $\boldsymbol{h}=$ & $\mathbf{2}$ & $\mathbf{4}$ & $\mathbf{6}$ & $\mathbf{8}$ \\
\hline$P^{*}$ & 84 & 88 & 92 & 95 \\
$Q^{*}$ & 512 & 418 & 388 & 384 \\
$r^{*}$ & 199 & 167 & 155 & 153 \\
$Z^{*}$ & 60,697 & 62,875 & 64,998 & 66,345 \\
$\mathrm{SL}^{*}$ & 0.9931 & 0.9853 & 0.9809 & 0.9804 \\
\hline
\end{tabular}

Table 22 Sensitivity analysis of the exponential model with respect to $\pi-\mathrm{L}-\mathrm{P}$ metric method $(p=2)$

\begin{tabular}{lcccc}
\hline $\boldsymbol{\pi}=$ & $\mathbf{1 5}$ & $\mathbf{2 5}$ & $\mathbf{3 5}$ & $\mathbf{4 5}$ \\
\hline$P^{*}$ & 60 & 80 & 100 & 120 \\
$Q^{*}$ & 446 & 432 & 398 & 341 \\
$r^{*}$ & 178 & 172 & 159 & 136 \\
$Z^{*}$ & 42,156 & 57,104 & 70,349 & 82,190 \\
$\mathrm{SL}^{*}$ & 0.9852 & 0.9860 & 0.9841 & 0.9759 \\
\hline
\end{tabular}

Table 23 Sensitivity analysis of the exponential model with respect to $a-$ L-P metric method $(p=2)$

\begin{tabular}{lcccc}
\hline $\boldsymbol{a}=$ & $\mathbf{0 . 5}$ & $\mathbf{1 . 5}$ & $\mathbf{2 . 5}$ & $\mathbf{3 . 5}$ \\
\hline$P^{*}$ & 90 & 90 & 90 & 90 \\
$Q^{*}$ & 512 & 441 & 388 & 384 \\
$r^{*}$ & 201 & 176 & 154 & 127 \\
$Z^{*}$ & 74,296 & 67,374 & 60,399 & 53,473 \\
$\mathrm{SL}^{*}$ & 0.9875 & 0.9856 & 0.9841 & 0.9790 \\
\hline
\end{tabular}

Table 24 Sensitivity analysis of the exponential model with respect to $C$ - L-P metric method $(p=1)$

\begin{tabular}{lcccc}
\hline $\boldsymbol{c}=$ & $\mathbf{6}$ & $\mathbf{9}$ & $\mathbf{1 2}$ & $\mathbf{1 5}$ \\
\hline$P^{*}$ & 82 & 88 & 94 & 100 \\
$Q^{*}$ & 512 & 432 & 421 & 416 \\
$r^{*}$ & 215 & 195 & 192 & 187 \\
$Z^{*}$ & 61,340 & 62,528 & 64,717 & 66,168 \\
$\mathrm{SL}^{*}$ & 0.9935 & 0.9928 & 0.9927 & 0.9923 \\
\hline
\end{tabular}


Table 25 Sensitivity analysis of the exponential model with respect to $h$ - L-P metric method $(p=1)$

\begin{tabular}{lcccc}
\hline $\boldsymbol{h}=$ & $\mathbf{2}$ & $\mathbf{4}$ & $\mathbf{6}$ & $\mathbf{8}$ \\
\hline$P^{*}$ & 84 & 88 & 92 & 95 \\
$Q^{*}$ & 478 & 443 & 389 & 385 \\
$r^{*}$ & 215 & 199 & 175 & 173 \\
$Z^{*}$ & 60,696 & 62,701 & 64,786 & 66,183 \\
$\mathrm{SL}^{*}$ & 0.9954 & 0.9935 & 0.9885 & 0.9883 \\
\hline
\end{tabular}

The second objective is the retailer's service level. It is the probability of not facing shortage during the lead time, which presented is as follows:

$$
\mathrm{SL}(P, r)=p(l D \leq r)=\int_{0}^{D} f_{1}(L) d l=\frac{r}{D(b-a)} .
$$

\section{Modeling with exponential distribution}

In this section, we obtain the optimal selling price, lot size, and reorder point $(P, Q$, and $r$ ) while the lead time has an exponential distribution with parameter $\lambda(L \sim$ $\exp (\lambda)$ and the following probability density function:

$$
f_{L}(l)=\lambda e^{-\lambda l} 0 \leq 1<\infty
$$

Therefore, in addition to the two cases shown in Figures 1 and 2, there is a probability that the delivery is received after the cycle time which is depicted in Figure 3 (Sheikh Sajadieh et al. 2009).

The expected total cost is given by

$$
\begin{aligned}
\mathrm{TC}(P, Q, r)= & C D+\frac{D A}{Q}+h \int_{0}^{r / D}\left(\frac{Q}{2}+r-D L\right) f_{L}(l) d l \\
& \frac{(r+Q)}{D}\left[\frac{\pi(D L-r)^{2}+h(Q+r-D L)^{2}}{2 Q}\right] f_{L}(l) d l \\
& +\int_{r}^{\frac{D}{D}}\left[\frac{Q}{2}\right) f_{L}(l) d l . \\
& +\int^{\infty} \pi\left(D L-r-\frac{(r+Q)}{D}\right.
\end{aligned}
$$

Table 26 Sensitivity analysis of the exponential model with respect to $\pi$ - L-P metric method $(p=1)$

\begin{tabular}{lcccc}
\hline $\boldsymbol{\pi}=$ & $\mathbf{1 5}$ & $\mathbf{2 5}$ & $\mathbf{3 5}$ & $\mathbf{4 5}$ \\
\hline$P^{*}$ & 60 & 80 & 100 & 120 \\
$\mathrm{Q}^{*}$ & 512 & 441 & 416 & 392 \\
$r^{*}$ & 209 & 198 & 187 & 176 \\
$Z^{*}$ & 41,843 & 56,861 & 70,168 & 81,873 \\
$\mathrm{SL}^{*}$ & 0.9929 & 0.9926 & 0.9923 & 0.9920 \\
\hline
\end{tabular}

Table 27 Sensitivity analysis of the exponential model with respect to $a$ - L-P metric method $(p=1)$

\begin{tabular}{lcccc}
\hline $\boldsymbol{a}=$ & $\mathbf{0 . 5}$ & $\mathbf{1 . 5}$ & $\mathbf{2 . 5}$ & $\mathbf{3 . 5}$ \\
\hline$P^{*}$ & 90 & 90 & 90 & 90 \\
$Q^{*}$ & 512 & 454 & 389 & 347 \\
$r^{*}$ & 230 & 204 & 175 & 156 \\
$Z^{*}$ & 74,152 & 67,204 & 60,288 & 53,267 \\
$\mathrm{SL}^{*}$ & 0.9934 & 0.9926 & 0.9909 & 0.9913 \\
\hline
\end{tabular}

Substituting Equation 6 in Equation 7, we have

$$
\begin{aligned}
\mathrm{TC}(P, Q, r)= & C D+\frac{D A}{Q}+h\left(r+\frac{Q}{2}-\frac{D}{\lambda}\right) \\
& +\frac{D^{2}(\pi+h)}{\lambda^{2} Q}\left(e^{-\frac{r \lambda}{D}}-e^{-\frac{(r+Q) \lambda}{D}}\right) .
\end{aligned}
$$

Thus, the annual profit is calculated as follows:

$$
\begin{aligned}
Z(P, Q, r)= & D(P-C)-\frac{D A}{Q}-h\left(r+\frac{Q}{2}-\frac{D}{\pi}\right) \\
& -\frac{D^{2}(\pi+h)}{\lambda^{2} Q}\left(e^{-\frac{r \lambda}{D}}-e^{-\frac{(r+Q) \lambda}{D}}\right) .
\end{aligned}
$$

In order to calculate the service level, we can write

$$
\begin{aligned}
\mathrm{SL}(P, r) & =P(l D \leq r)=\int_{0}^{\frac{r}{D}} f_{l}(L) d l \\
& =1-\exp \left(-\frac{\lambda r}{D}\right) .
\end{aligned}
$$

\section{Solution procedure}

There are different methods to change a multi-objective optimization to a single-objective optimization. In this paper, we apply the weighting method that is useful and simple in concept and implementation. Also, the L-P metric method which is one of the famous methods of MCDM is applied in this paper. In this technique, the objective functions have the most proximity to their ideal values. These methods are explained respectively.

\section{Weighting method}

Considering a weight for each objective, the new objective function is obtained from the sum of objective functions with the corresponding weights. Therefore, the model for uniform and exponential lead time would respectively be as follows: 

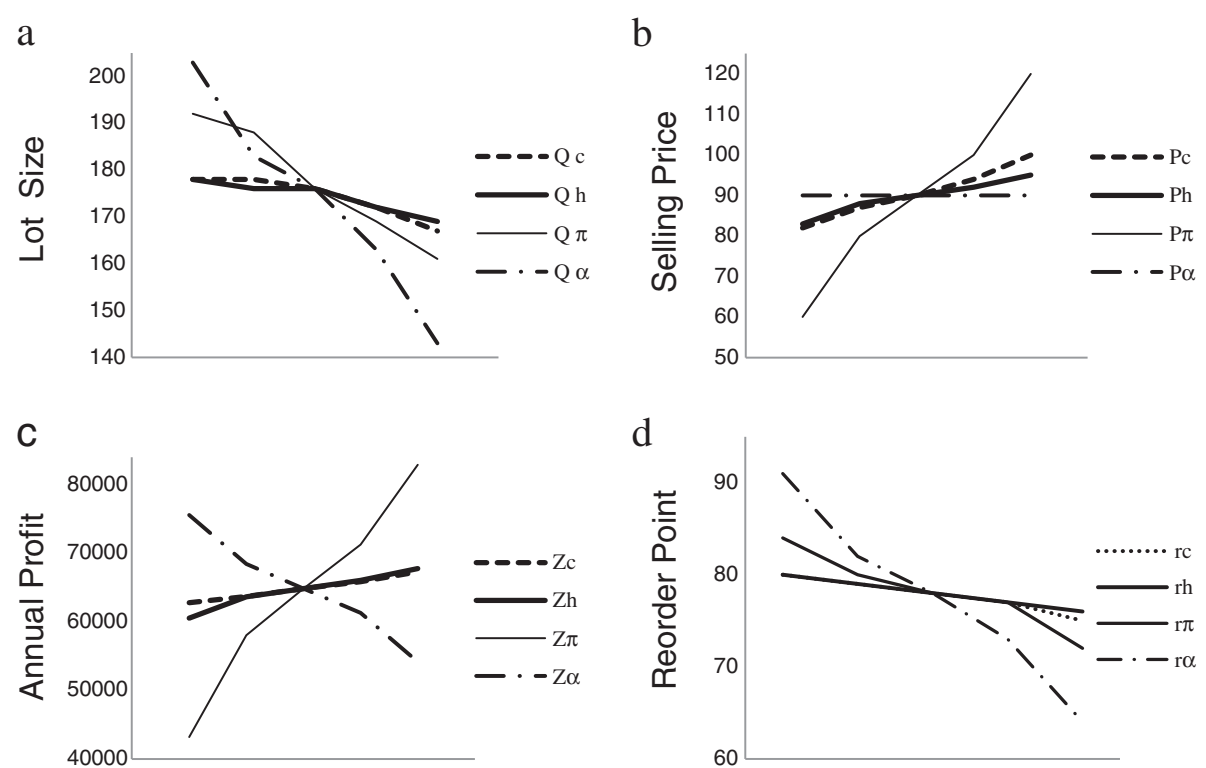

d
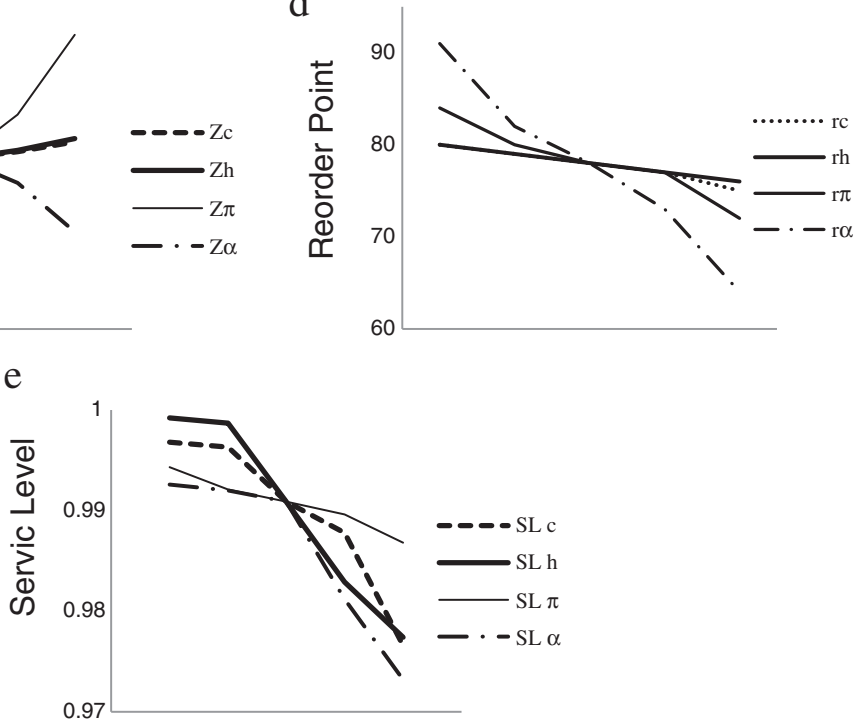

Figure 7 Effect of key parameters on (a) Q, (b) P, (c) Z, (d) r, and (e) SL (uniform model, L-P metric method $p=2$ ).

$$
\begin{aligned}
& \operatorname{Max}: W_{1} \cdot\left[D(P-C)-\frac{D A}{Q}-\frac{h}{2}(Q+2 r-D(a+b))\right. \\
& +\frac{h\left(D^{3} a^{3}+3 r^{2} D b-3 r D^{2} a^{2}-r^{3}\right)}{6 Q D(b-a)} \\
& +\frac{3 h r D(a+b)-h D^{2}\left(a^{2}+b^{2}+a b\right)}{6 Q} \\
& \left.-\frac{\pi(D b-r)^{3}}{6 Q D(b-a)}\right]+W_{2} \cdot\left[\frac{r}{D(b-a)}\right]
\end{aligned}
$$

S.t $P, Q, r \geq 0$ and $W_{1}+W_{2}=1$.

$$
\begin{aligned}
\operatorname{Max}: W_{1} \cdot & {\left[D(P-C)-\frac{D A}{Q}-h\left(r+\frac{Q}{2}-\frac{D}{\pi}\right)\right.} \\
& \left.-\frac{D^{2}(\pi+h)}{\lambda^{2} Q}\left(e^{-\frac{r \lambda}{D}}-e^{\left.-\frac{(r+Q) \lambda}{D}\right)}\right)\right] \\
+ & W_{2} \cdot\left[1-\exp \left(-\frac{\lambda r}{D}\right)\right]
\end{aligned}
$$

S.t $P, Q, r \geq 0$ and $W_{1}+W_{2}=1$.

\section{L-P metric method}

In the L-P metric method, the distance of any present solution from the ideal solution is minimized (Banke et al. 2008):

$$
L-P=\left\{\sum_{j=1}^{k} \gamma_{j}\left(f_{j}\left(x^{* j}\right)-f_{j}(x)\right)^{p}\right\}^{1 / p}
$$

where $x^{\prime \prime}$ shows the ideal solution for optimizing the $j$ th objective, $x$ is the assumed solution, and $Y_{j}$ indicates the significance degree for the $j$ th objective. $1 \leq p \leq \infty$ is the parameter that specifies the L-P family. The $p$ value indicates the emphasis level on the existing deviations. Therefore, the larger the $p$, the more emphasis will be there on the largest deviations. The values $p=1, p=2$, and $p=\infty$ are commonly used. In the present approach, we consider $p=1$ and $p=2$. When $p=1$, the deviation is simply summed over all attributes, and when $p=2$, the metric measures the shortest geometric distance between two points, which is a straight line. Other values of $p$ are not as easily interpreted, but they may be reasonable choices in a 

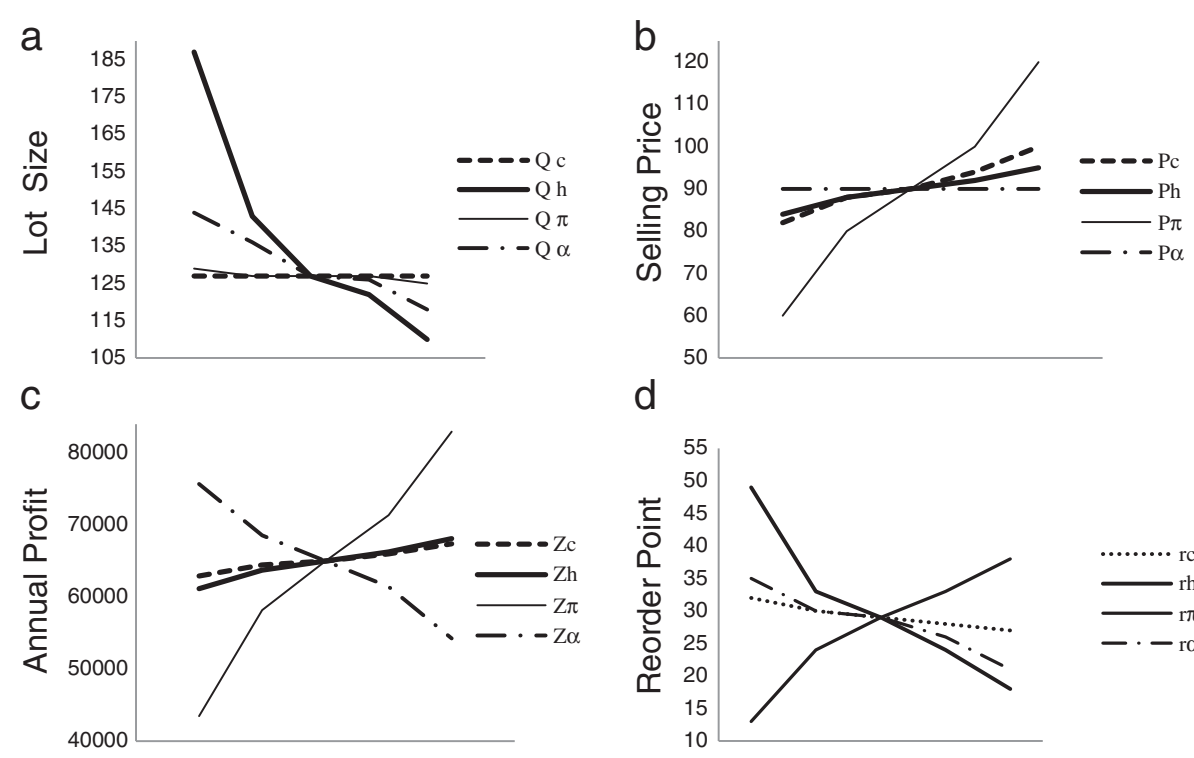

d
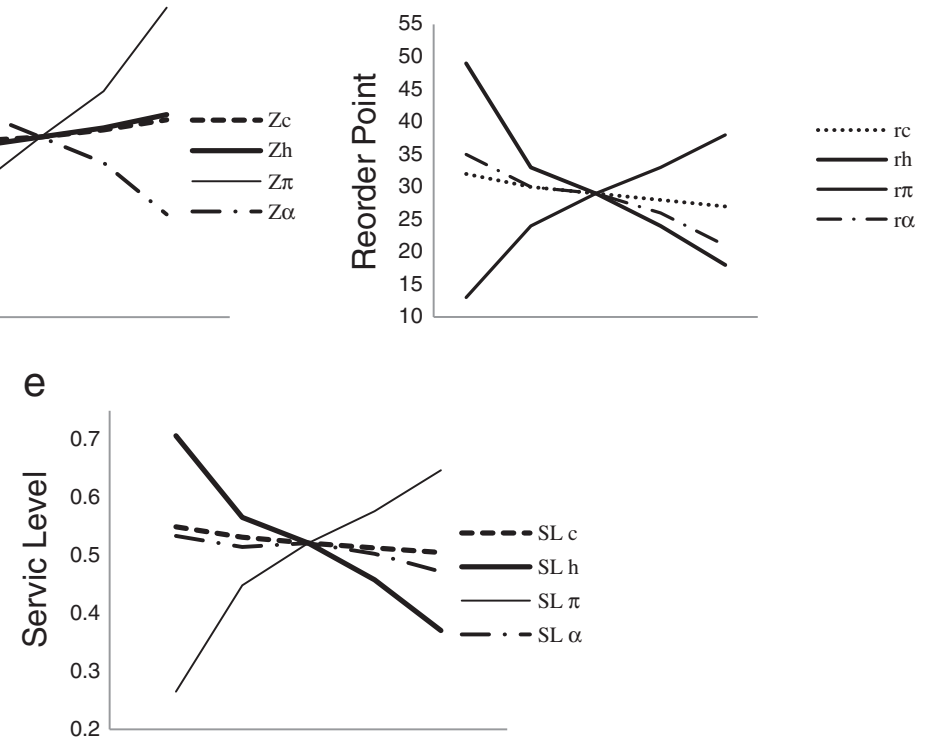

Figure 8 Effect of key parameters on (a) Q, (b) P, (c) Z, (d) r, and (e) SL (exponential model, weighting method).

given application. The $p$ value depends on decision maker measures. The L-P method is affected by the objective measurement scale. Thus, the following formula is used:

$$
L-P=\left\{\sum_{j=1}^{k} \gamma_{j}\left[\frac{f_{j}\left(x^{* j}\right)-f_{j}(x)}{f_{j}\left(x^{* j}\right)}\right]^{p}\right\}^{1 / p}
$$

Therefore, the model for uniform lead time is given by

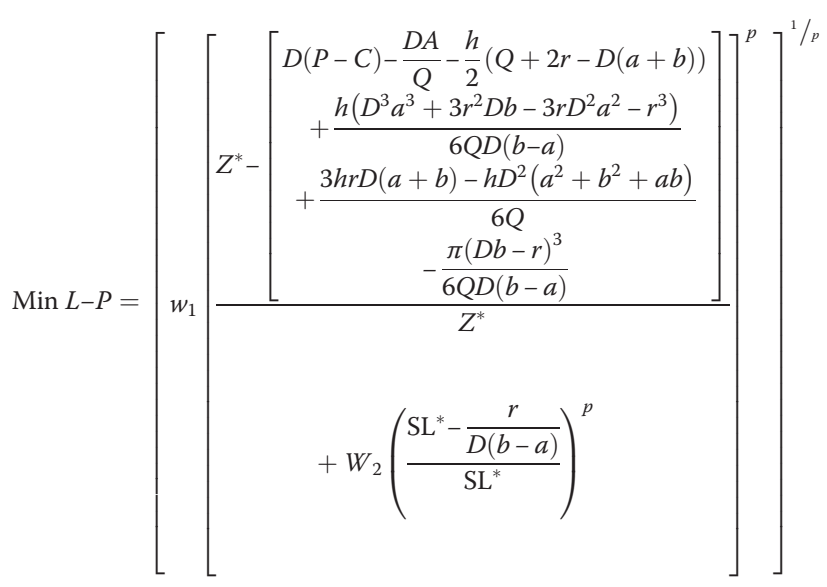

If lead time is exponential, we have the following objective function:

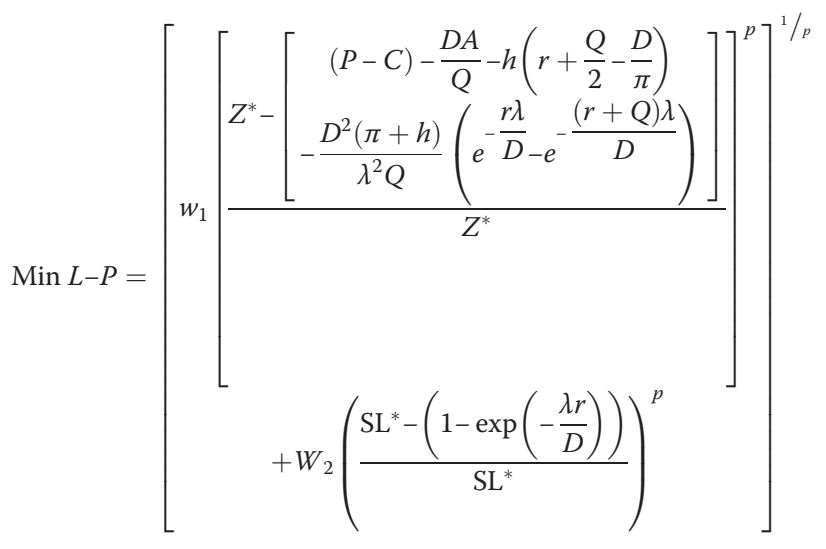

\section{Genetic algorithm}

Most researchers have used genetic algorithm to solve optimization problems (Taleizadeh et al. 2010; Maiti et al. 2009; Pasandideh et al. 2011). Considering the complexity of the nonlinear model, genetic algorithm is applied to find the optimal solution. GA was first 

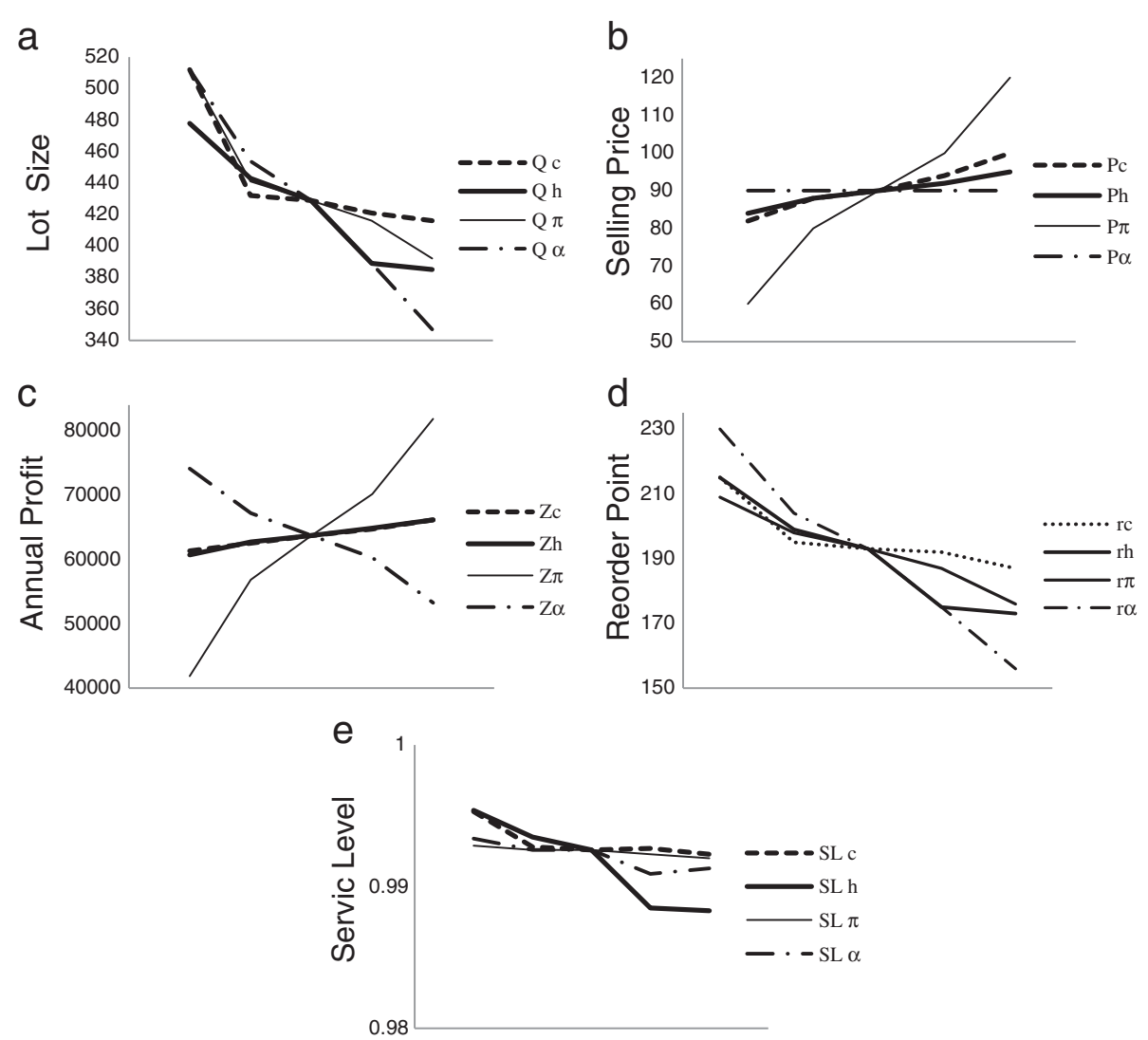

Figure 9 Effect of key parameters on (a) Q, (b) $\mathrm{P}_{,}$(c) Z, (d) r, and (e) SL (exponential model, L-P metric method $p=1$ ).

presented by Holland in 1975 and was developed based on the principles of genetics and evolution (Haupt and Haupt 2004). Genetic algorithm begins to work with an initial population of solutions (chromosomes). New solutions are developed by crossover and mutation operators. To form the new population, the best solutions will be selected from the existing population using a fitness function. The solutions improve from one generation to another so that the desirable solution is obtained gradually.

\section{Chromosome}

Chromosome is a series of bits in which the coded forms of all suitable or unsuitable are placed. A suitable design of chromosome structure is an important part of genetic algorithm. In our algorithm, a string is designed with a length of $k$ in which the first, second, and third onethirds indicate reorder point, selling price, and lot size, respectively.

\section{Population}

A group of chromosomes is called a population. The initial population is generated completely randomly, and the number of chromosomes in each population becomes the population size $(N)$. The value of $N$ is important and must be specified based on the type of problem and its coding. In the present paper, the population size is set to $400(N=400)$.

\section{Crossover}

Crossover operator is applied on two parents, and a new child is generated as a result. We consider a two-point crossover in the manner that two crossover points are randomly chosen from the string, and then the two parent chromosomes are interchanged between these points to produce two new children.

\section{Mutation}

The second operator in the genetic algorithm is the mutation operator which prevents the algorithm to fall in the local optimum. In our algorithm, we use random mutation.

\section{Stopping criterion}

Stopping criterion is the final stage in the genetic algorithm. There are several indexes in this regard. Here, the maximum generation reproduction rule is used, i.e., once the generation counter reaches a certain number, the algorithm will stop. This rule has been used by several researchers. Figure 4 depicts the proposed genetic algorithm. 


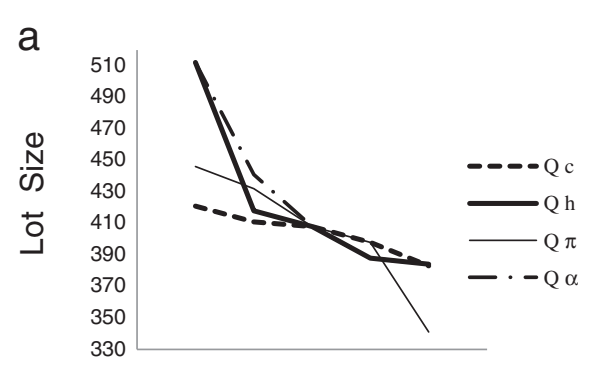

C

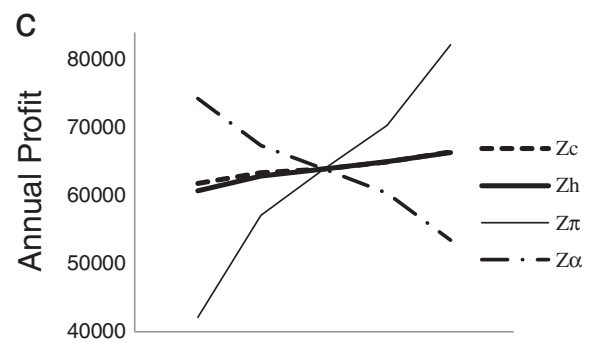

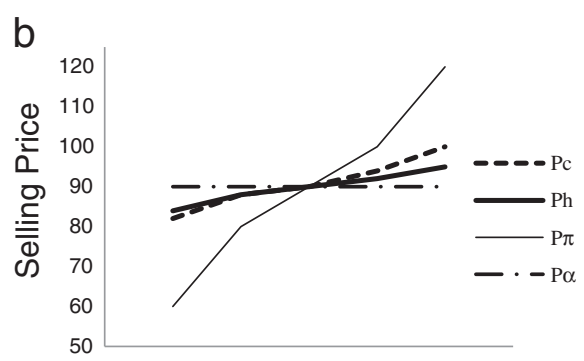

d

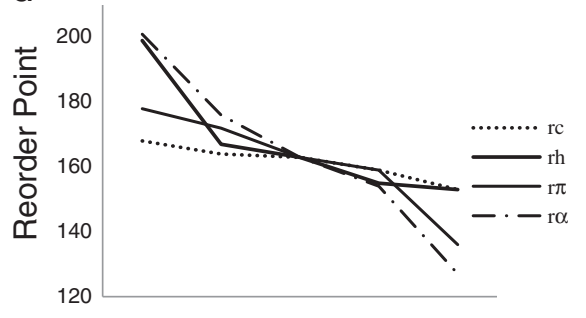

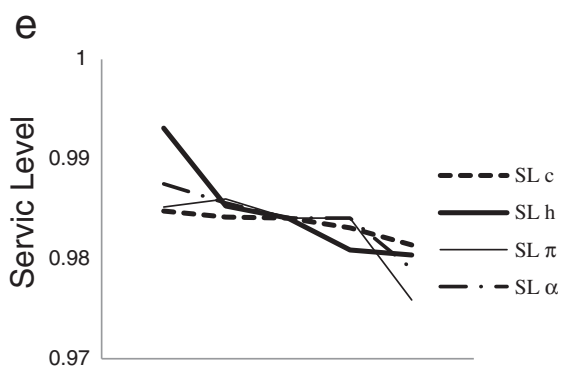

Figure 10 Effect of key parameters on (a) Q, (b) $\mathrm{P}$, (c) Z, (d) r, and (e) SL (exponential model, L-P metric method $p=2$ ).

\section{Numerical example and sensitivity analysis}

In this section, we illustrate the quality of our model by presenting some examples. We will also perform sensitivity analysis for the key parameters $(\pi, C, h$, and $\alpha$ ) of the model. Assume that the retailer faces a linear demand function of $D=1,000-\alpha p$, where $\alpha$ is the demand elasticity coefficient which is equal to 2 . The cost of each ordering is US\$25, while the holding cost for each unit of items is US\$5/year and the shortage cost of each unit of items is US\$30/year; $a=0$ and $b=35$ (days) if the demand is distributed uniformly, and $\lambda=17.5$ if it is distributed exponentially. Therefore, the average lead time is the same in both cases.

We consider $p=1$ and $p=2$ for the L-P metric method and different objective weights for the weighting method. The obtained optimal solution is shown in Tables 2 and 3.

\section{Sensitivity analysis}

To select a suitable strategy for the retailer, we consider the effect of parameters $\pi, C, h$, and $\alpha$ on decision variables and objective functions. The optimal solutions are shown in Tables 3, 4, 5, 6, 7, 8, 9, 10, 11, 12, 13, and 14 while the results of sensitivity analysis are shown in Figures 4, 5, and
6. In addition, the weights of the first and second objective functions are considered 0.6 and 0.4 , respectively.

As it can be seen in the figures and tables, by increasing the cost parameters, the selling price $\left(p^{*}\right)$ and profit $\left(Z^{*}\right)$ will increase. Moreover, when demand elasticity increases, the lot size $\left(Q^{*}\right)$ will decrease. This happens because the higher the sensitivity of items to the selling price, the more will be the tangible demand decrease against high price. Moreover, reorder point has a direct relation with service level.

As Tables 4, 5, 6, 7, 8, 9, 10, 11, 12, 13, 14, 15, 16, 17, 18, 19, 20, 21, 22, 23, 24, 25, 26, and 27 and Figures 6, 7, 8, 9, and 10 show, the service level in the L-P metric method is larger while the annual profit of the weighting method is larger. In addition, in the L-P metric method, the profit is larger for larger $p$, but this does not hold for service level.

\section{Conclusions}

In this paper, a multi-objective inventory model is presented which includes the maximization of the retailer's profit along with the maximization of customer service level. The demand is assumed as a general function of price. In addition, planning horizon is considered infinite. The stochastic lead time is assumed to be uniformly and exponentially 
distributed, and the shortage is allowed. The proposed model is a complex (a multi-objective nonlinear model). Therefore, the optimal solution of the selling price, lot size, and reorder point is obtained using the genetic algorithm. The weighting and L-P metric methods are used to change a multi-objective function to a single-objective function. $\mathrm{Nu}$ merical examples and sensitivity analysis on the key parameters $(\pi, C, h$, and $\alpha)$ of the model are presented. The results show that the retailer's profit in uniform distribution is larger, while lot size and reorder point of the exponential model is larger. In addition, increasing the cost parameters will increase the selling price $\left(p^{*}\right)$ and the profit $\left(Z^{*}\right)$. Moreover, when the demand elasticity $(\alpha)$ increases, the lot size $\left(Q^{*}\right)$ will decrease. In addition, the reorder point has a direct relation with the service level. In addition, using the L-P metric method, a higher service level is obtained, but the annual profit of the weighting method is larger.

In the future, it may be interesting to examine a scenario in which the system deals with stochastic consumer demand as well as stochastic lead time in order to define the system more accurately. Considering a multi-period system and planning of the prices of the product as a dynamic pricing may be a scope for future research. The proposed GA variants that employ various crossover and mutation operations could be another area of future interest. New solution methodology based on tabu search or heuristic methods can be developed to obtain new optimal solutions for the multi-objective problem. In this case, conducting more numerical tests to justify the developed algorithm would be necessary. Additionally, uncertainty of costs and demand parameters can be taken into account in the model, and new solution methodologies including uncertainty can be developed via fuzzy models.

\section{Authors' contributions}

Zeinab Hosseini drafted the manuscript. She formulated the stochastic joint pricing and inventory problem and designed the solution procedure. Reza Ghasemy Yaghin defined the research area, carried out the finalization of joint pricing and inventory model in multiple objective environment. He supposed multiple objective optimization solution procedures in order to solve the aforementioned model. Maryam Esmaeili supposed and analyzed the mathematical properties of the developed model. Numerical studies had been provided by her. She also supervised the research.

\section{Acknowledgements}

The authors would like to thank anonymous referees for their valuable comments and helpful suggestions on improving the quality of the paper.

\footnotetext{
Author details

'Department of Industrial Engineering, Alzahra University, Tehran, Iran. ${ }^{2}$ Department of Industrial Engineering, Amirkabir University of Technology, Tehran, Iran.
}

Received: 22 May 2013 Accepted: 10 October 2013 Published: \#PUBLICATION_DATE

\section{References}

Abad PL (2003) Optimal pricing and lot-sizing under conditions of perishability, finite production and partial backordering and lost sale. Eur J Oper Res 144:677-685
Abad PL (2008) Optimal price and order size under partial backordering incorporating shortage, backorder and lost sale costs. Int J Prod Econ 114:179-186

Agrell PJ (1995) A multicriteria framework for inventory control. International Journal of Production Economics 41:59-70

Branke J, Deb K, Miettinen K, Slowinski R (editors) (2008) Multi objective optimization. Interactive and evolutionary approaches. Springer, Berlin, Germany

Dye C-Y (2007) Joint pricing and ordering policy for a deteriorating inventory with partial backlogging. Omega 35:184-189

Dye C-Y, Hsieh T-P (2010) A particle swarm optimization for solving joint pricing and lot-sizing problem with fluctuating demand and unit purchasing cost. Comput Math Appl 60:1895-1907

Dye C-Y, Hsieh T-P (2013) Joint pricing and ordering policy for an advance booking system with partial order cancellations. Appl Math Model 37(6):3645-3659

Esmaeili M (2009) Optimal selling price, marketing expenditure and lot size under general demand function. Int J Adv Manuf Tech 45:191-198

Hosseini Z, Esmaeili M, Ghasemy Yaghin R (2012) A multiple objective approach for joint inventory and pricing planning model with stochastic lead times. Paper presented at the 8th International Industrial Engineering Conference. Amirkabir University of Technology, Tehran. 15-16 February 2012

Haupt RL, Haupt SE (2004) Practical genetic algorithms. John Wiley \& Sons, Hoboken, New Jersey

Islam S (2008) Multi-objective marketing planning inventory model: a geometric programming approach. Appl Math Comput 205:238-246

Lee J (2011) Inventory control by different service levels. Appl Math Model 35:497-505

Liang S-K, Chu P, Yang K-L (2008) Improved periodic review inventory model involving lead time with crashing components and service level. Int J Syst Sci 39(4):421-426

Mukhopadhyay S, Mukherjee RN, Chaudhuri KS (2004) Joint pricing and ordering policy for a deteriorating inventory. Comput Ind Eng 47:339-349

Moslemi H, Zandieh M (2011) Comparisons of some improving strategies on MOPSO for multi-objective $(r, Q)$ inventory system. Expert Syst Appl 38:12051-12057

Mandal NK, Roy TK, Maiti M (2005) Multi-objective fuzzy inventory model with three constraints: a geometric programming approach. Fuzzy Set Syst 150:87-106

Maity K, Maiti M (2008) A numerical approach to a multi-objective optimal inventory control problem for deteriorating multi-items under fuzzy inflation and discounting. Comput Math Appl 55:1794-1807

Maiti AK, Maiti MK, Maiti M (2009) Inventory model with stochastic lead-time and price dependent demand incorporating advance payment. Appl Math Model 33:2433-2443

Padmanabhan G, Vrat P(1990) Analysis of multi-item inventory systems under resource constraints: A non-linear goal programming approach. Engineering Cost and Production Economics 20:121-127

Pasandideh SHR, Akhavan Niaki ST, Tokhmehchi N (2011) A parameter-tuned genetic algorithm to optimize two-echelon continuous review inventory systems. Expert Syst Appl 38:11708-11714

Roy TK, Maiti M (1998) Multi objective inventory models of deteriorating items with some constraints in a fuzzy environment. Comput Oper Res 25(12):1085-1095

Sana SS (2011) The stochastic EOQ model with random sales price. Appl Math Comput 218:239-248

Sadjadi SJ, Yazdian SA, Shahanaghi K (2012) Optimal pricing, lot-sizing and marketing planning in a capacitated and imperfect production system. Comput Ind Eng 62:349-358

Sheikh Sajadieh M, Akbari Jokar MR (2009) An integrated vendor-buyer cooperative model under stochastic supply lead-time. Int J Adv Manuf Tech 41:1043-1050

Sheikh Sajadieh M, Akbari Jokar MR, Modarres M (2009) Developing a coordinated vendor-buyer model in two-stage supply chains with stochastic lead-times. Comput Oper Res 36:2484-2489

Taleizadeh A, Akhavan Niaki ST, Aryanezhad M-B, Fallah Tafti A (2010) A genetic algorithm to optimize multiproduct multi constraint inventory control systems with stochastic replenishment intervals and discount. Int J Adv Manuf Tech 51:311-323

Tsou C-S (2008) Multi-objective inventory planning using MOPSO and TOPSIS. Expert Syst Appl 35:136-142

Tsou C-S (2009) Evolutionary Pareto optimizers for continuous review stochastic inventory systems. Eur J Oper Res 195:364-371

Whitin T-M (1955) Inventory control and price theory. Manage Sci 2:61-68

\section{\#DIGITAL OBJECT IDENTIFIER}

Cite this article as: Hosseini et al:: A multiple objective approach for joint ordering and pricing planning problem with stochastic lead times. Journal of Industrial Engineering International \#CITATION 